\title{
RESENAS BIBLIOGRAFICAS
}

\section{RANDALL, Alan. Economía de los recursos naturales y política ambiental. México: Limusa, 1985, 474 p.}

El objetivo de este libro es presentar como trata el análisis económico la problemática de los recursos naturales; así como la función que desempeña en el estudio. evaluación y desarrollo de la política ambiental.

Si bien la Economía es la disciplina central y unificadora de esta obra, quedan integrados a ella conocimientos provenientes de las ciencias naturales y aspectos jurídicos, políticos y administrativos.

El contenido se distribuye entre veinticuatro capítulos divididos en siete secciones. El capítulo 1 considera los problemas de los recursos naturales y ambientales que padece actuaimente el mundo. El capítulo 2 define a los recursos y señala algunos aspectos importantes de las políticas referidas a ellos.

El interés por la temática objeto de estudio de esta obra suele reunir a un grupo muy heterogéneo de estudiosos, algunos de los cuales han tenido un ligero contacto formal con la Economía; por lo tanto, en los capítulos 3 al 5 se realiza un breve bosquejo de como funciona una economía moderna y se presenta una sencilla exposición de la teoría del consumidor, la empresa y el equilibrio del mercado.

Los capítulos 6 y 7 estudian los criterios de eficiencia económica y bienestar social, relacionándolos con los derechos de propiedad. A su vez, el capítulo 8 se ocupa de las imperfecciones de los mercados. En conjunto, estos capítulos constituyen uno de los aspectos medulares del análisis de los problemas de la economía de los recursos naturales.

La sección siguiente pone en juego al tiempo. Considera cómo las decisiones tomadas en un período ayudan a conformar el conjunto de oportunidades futuras. Así, el capítulo 9 trata acerca de las decisiones de ahorro e inversión; el 10 examina la asignación de los recursos naturales en el transcurso del tiempo y el 11 estudia la lógica de la conservación.

Los análisis teóricos de las secciones anteriores ponen de manifiesto la función esencial que cumplen las instituciones en la formación de los conjuntos de oportunidades individuales y en los resultados de la interacción económica; de allí que los capítulos 12 al 14 estén dedicados a describir el marco institucional inherente a la problemática referida.

Las técnicas de análisis empírico se desarrollan en los próximos tres capítulos, dedicando el resto de la obra al análisis integrado de los problemas de políticas de los recursos naturales y ambientales. Es decir que, se toman casos concretos, se plantean problemas de política y se busca su solución aplicando los conceptos téricos, las técnicas empíricas, teniendo siempre en cuenta los conceptos institucionales, todos ellos explicados en las secciones anteriores.

El libro, de carácter introductorio, está dedicado a aquellos que se inician en el estudio de la economía de los recursos naturales y la política ambiental. Es una obra de lectura ordenada y clara, que recurre con frecuencia a ejemplos y proporciona una interesante guía bibliográfica especializada. 